CLINICAL STUDY

\title{
Increased serum osteoprotegerin in disorders characterized by persistent immune activation or glucocorticoid excess - possible role in bone homeostasis
}

\author{
Thor Ueland ${ }^{1,3}$, Jens Bollerslev ${ }^{1}$, Kristin Godang ${ }^{1}$, Fredrik Müller ${ }^{3}$, Stig S Frøland ${ }^{2,3}$ and Pål Aukrust ${ }^{2,3}$ \\ ${ }^{1}$ Section of Endocrinology, ${ }^{2}$ Section of Clinical Immunology and Infectious Diseases and ${ }^{3}$ Research Institute for Internal Medicine, Medical Department, \\ University of Oslo, Rikshospitalet, N-0027 Oslo, Norway \\ (Correspondence should be addressed to T Ueland, Section of Endocrinology, Medical Department, National University Hospital, N-O027 Oslo, Norway; \\ Email: thor.ueland@klinmed.uio.no)
}

\begin{abstract}
Objective: To investigate the possible role of osteoprotegerin (OPG) in bone metabolism in humans by measuring serum levels of OPG in five well-characterized patient populations with known or suspected pathology in bone homeostasis, but with differences in the pathogenesis of these disturbances.

Design: The study comprised 34 patients with Cushing's syndrome (CS), 24 acromegalic patients, 16 patients with growth hormone deficiency (GHD), 29 HIV-infected patients, 25 patients with common variable immunodeficiency (CVI) and 59 age- and sex-matched healthy controls (CTR).

Methods: Serum levels of tumor necrosis factor (TNF)- $\alpha$, OPG, C-terminal telopeptides of Type-I collagen (CTX-I) and osteocalcin were determined in all study subjects as well as cortisol (CS and CTR) and IGF-I (acromegaly, GHD and CTR).

Results: OPG levels were significantly elevated in both CVI (median increase $\sim 32 \%, P<0.05$ ) and HIV-infected patients with especially high levels in the latter group $(\sim 52 \%, P<0.001)$, significantly correlated with increased TNF $\alpha$ levels $(r=0.47, P<0.02)$. Also CS patients had elevated serum OPG $(\sim 24 \%, P<0.01)$, significantly correlated with increased serum cortisol $(r=0.35, P<0.05)$. In contrast, OPG levels in acromegalic and GHD patients were not different from healthy controls. No relationships were found between OPG levels and CTX-I or osteocalcin.

Conclusions: These findings suggest that enhanced OPG levels may be a compensatory response to enhanced osteoclast activity or negative bone remodeling balance in some conditions, but may also be a parameter of enhanced activity in the OPG system possibly correlated to enhanced activity of other members of the TNF family.
\end{abstract}

European Journal of Endocrinology 145 685-690

\section{Introduction}

An integrated network of hormones, growth factors and cytokines regulates the balance between bone resorption and bone formation. Although proinflammatory cytokines such as interleukin (IL)-1, tumor necrosis factor (TNF)- $\alpha$, IL-6 and IL-11 are potent inducers of osteoclastic bone resorption in vitro, their effects on osteoclast formation and activity are dependent on the presence of osteoblastic stromal cells $(1-3)$. This indicates that osteoblasts may couple bone formation and resorption through effects on osteoclasts, possibly mediated by locally produced factors. Recently, osteoprotegerin (OPG), and its cognate ligand, receptor activator of NF- $\kappa \mathrm{B}$ ligand (RANKL), have been identified as candidate factors in the paracrine signaling between osteoblasts and osteoclasts (4). OPG is a member of the TNF receptor superfamily $(5,6)$ which acts as a soluble receptor that inhibits osteoclast differentiation by binding RANKL and competitively inhibiting interaction between RANKL and its receptor, RANK, on the osteoclast surface (4). Thus, overexpression of OPG in transgenic mice resulted in severe osteopetrosis with a marked decrease in trabecular osteoclasts (5), while OPG knock-out mice developed severe osteoporosis $(7,8)$, and it has been suggested that effects of various hormones and cytokines on osteoclastogenesis may depend on the balance between OPG and RANKL.

Although extensive research has been directed against the effects of OPG in cell cultures and various animal models, the role of circulating OPG in humans is virtually unknown. In fact, except for a report of high circulating OPG levels in postmenopausal women with 
osteoporosis, it is not known how OPG levels change under various pathological conditions. To further elucidate the possible role of OPG in bone metabolism in humans, in the present study we measured serum levels of OPG in five well-characterized patient populations, all with known or suspected pathology in bone homeostasis, but with differences in the pathogenesis of these disturbances.

\section{Materials and methods}

\section{Study population}

A total of 187 individuals were included in the present investigation (Table 1). The study population consisted of five different well-characterized patient populations and one group of healthy controls. Of the patient groups, three had disturbed bone metabolism related to a primary endocrine disorder and two were immunologic disorders with known or suspected disturbances in bone homeostasis.

Endocrine disorders This group compromised 74 patients: 34 with endocrine Cushing's syndrome (CS), 24 with acromegaly and 16 with growth hormone (GH) deficiency (GHD). CS was diagnosed based on typical history and objective findings of CS. The diagnosis was confirmed by abnormal diurnal rhythm of serum cortisol, resistance to conventional 2-days dexamethasone suppression test, and elevated 24-h urine free cortisol level. Acromegaly was defined by non-suppressible serum levels of $\mathrm{GH}(>5 \mathrm{mU} / \mathrm{l})$ by oral glucose tolerance test. All patients had clinically active disease and had not been treated previously. GHD was defined in a clinical context by a maximal GH peak of less than $7 \mathrm{mU} / \mathrm{l}$ after an insulin tolerance test (blood glucose $<2.2 \mathrm{mmol} / \mathrm{l}$ and/or a $50 \%$ reduction of initial blood glucose). GHD was acquired in adulthood $(>18$ years old) and was likely to have existed for at least 24 months. All patients had deficiencies of other pituitary hormones and received stable replacement therapy for at least 6 months before blood sampling.
Immunologic disorders We have recently demonstrated indication of disturbed bone metabolism in human immunodeficiency virus (HIV)-infected patients (9) and in patients with common variable immunodeficiency (CVI) (10). Both groups of patients are characterized by a persistent immune activation in vivo particularly in the TNF system $(11,12)$, and we have suggested that the disturbed bone homeostasis in these patients is related to enhanced TNF activity $(9,10)$. The HIV-infected patients $(n=29)$ were clinically classified according to criteria from Centers for Disease Control and Prevention (CDC): 7 patients as asymptomatic HIV-infected patients (CDC group A), 7 patients as symptomatic non-AIDS patients (CDC group B) and 15 as AIDS patients (CDC group C) (13). Seventeen patients received antiretroviral therapy (12 zidovudine, 1 didanosine and 4 zidovudine in combination with lamivudine), but none received protease inhibitorcontaining regimes. Seventeen received Pneumocystis carinii prophylaxis ( 2 aerosolized pentamidine, 10 dapsone and 5 trimetoprim-sulfametoxazole). CVI ( $n=$ 25) was defined as previously described $(14,15)$. All patients had severely reduced serum immunoglobulin G (IgG) levels in at least two samples and experienced recurrent sinopulmonary infections before Ig treatment. At the time of the study all patients had been treated with subcutaneous self-administered Ig for a minimum of 12 months, and all had IgG levels $>5.0 \mathrm{~g} / \mathrm{l}$ during the last 3 months before blood collection. We have previously defined a subgroup of CVI patients $\left(\mathrm{CVI}_{\text {Hyper }}\right)$ characterized by persistent immune activation in vivo, low numbers of $\mathrm{CD}^{+} \mathrm{T}$ cells in peripheral blood, and increased occurrence of splenomegaly compared with other CVI patients $\left(\mathrm{CVI}_{\mathrm{Norm}}\right)(12,16)$. Classifying patients in the present study accordingly, 13 were classified as $\mathrm{CVI}_{\mathrm{Hyper}}$ and 12 as $\mathrm{CVI}_{\text {Norm }}$.

At the time of the study, none of the patients had any signs of symptoms of acute or exacerbation of chronic infections. All patients had serum creatinine $<100 \mu \mathrm{mol} / \mathrm{l}$ and alanine aminotransferase levels $<50 \mathrm{U} / \mathrm{ml}$. None of the patients had any recent history of extended bed rest and none was abusing drugs or alcohol.

Table 1 Characteristics of the study group. Data are given as medians and 25th to 75th percentiles unless otherwise stated.

\begin{tabular}{lllllll}
\hline & \multicolumn{1}{c}{$\begin{array}{c}\text { Controls } \\
(n=59)\end{array}$} & $\begin{array}{c}\text { Acromegaly } \\
(n=24)\end{array}$ & $\begin{array}{c}\text { GHD } \\
(n=16)\end{array}$ & $\begin{array}{c}\text { CS } \\
(n=34)\end{array}$ & $\begin{array}{c}\text { HIV } \\
(n=29)\end{array}$ & $\begin{array}{c}\text { CVI } \\
(n=25)\end{array}$ \\
\hline Median age in years (range) & $44(23-66)$ & $52(32-77)$ & $48(26-58)$ & $43(21-69)$ & $38(24-60)$ & $43(24-66)$ \\
Males/females & $30 / 29$ & $12 / 12$ & $0 / 16$ & $8 / 26$ & $20 / 9$ & $12 / 13$ \\
C-telopeptide $(\mu \mathrm{mol} / \mathrm{l})$ & $3.2(2.3-4.1)$ & $6.1(3.6-7.8)^{\mathrm{b}}$ & $1.8(1.1-3.4)^{\mathrm{a}}$ & $3.9(3.0-5.0)^{\mathrm{a}}$ & $3.0(1.7-4.3)$ & $4.0(3.3-7.6)^{\mathrm{a}}$ \\
Osteocalcin $(\mathrm{nmol} / \mathrm{l})$ & $1.2(0.8-1.5)$ & $1.5(1.0-2.6)^{\mathrm{a}}$ & $0.3(0.2-0.4)^{\mathrm{b}}$ & $0.9(0.5-1.3)^{\mathrm{a}}$ & $0.7(0.2-0.9)^{\mathrm{b}}$ & $1.0(0.5-1.7)$ \\
TNF $\alpha(\mathrm{pg} / \mathrm{ml})$ & $16(13-19)$ & $20(17-24)^{\mathrm{b}}$ & $20(17-29)^{\mathrm{b}}$ & $15(10-20)$ & $46(33-68)^{\mathrm{b}}$ & $41(31-58)^{\mathrm{b}}$ \\
IGF-I $(\mathrm{nmol})$ & $21(18-25)$ & $56(36-82)^{\mathrm{b}}$ & $12(3-16)^{\mathrm{b}}$ & $575(499-680)^{\mathrm{b}}$ & & \\
Cortisol $(0800 \mathrm{~h})(\mathrm{nmol} / \mathrm{l})$ & $380(300-442)$ & & 0.14 & $0.45^{\mathrm{c}}$ \\
Correlation C-telopeptide-osteocalcin & $0.38^{\mathrm{d}}$ & $0.63^{\mathrm{e}}$ & 0.47 & 0.17 & & \\
\hline
\end{tabular}

${ }^{\mathrm{a}} P<0.05,{ }^{\mathrm{b}} P<0.001$ versus controls. Correlation analysis (Spearman): ${ }^{\mathrm{c}} P<0.05,{ }^{\mathrm{d}} P<0.01,{ }^{\mathrm{e}} P<0.001$. 
Healthy controls Fifty-nine healthy blood donors were recruited as controls. The group was comprised of 30 men (median age 42 years, range 30-64 years) and 29 women (median age 44 years, range 23-66 years) (Table 1).

\section{Blood sampling protocol}

Blood samples for the study were drawn between 0800 and $1000 \mathrm{~h}$ after an overnight fast. Peripheral venous blood was drawn into sterile vacuum blood collection tubes without any additives (Becton Dickenson, San Jose, CA, USA). The tubes were immediately immersed in melting ice and allowed to clot for $<1 \mathrm{~h}$ before centrifugation at $1000 \boldsymbol{g}$ for $10 \mathrm{~min}$. Serum was collected and stored at $-80{ }^{\circ} \mathrm{C}$ in multiple aliquots until analysis, and was thawed only once.

\section{Analysis of osteoprotegerin}

Serum levels of OPG were quantified by enzyme immunoassay (EIA) using commercially available matched antibodies (R\&D Systems, Minneapolis, MN, USA). Briefly, wells were coated overnight with monoclonal mouse anti-human OPG antibody (clone 69127.11; $1 \mu \mathrm{g} / \mathrm{ml}$ in sterile phosphate-buffered saline (PBS)). Standard was recombinant OPG (R\&D Systems; $15.6-2000 \mathrm{pg} / \mathrm{ml})$. Subsequent steps included biotinylated polyclonal goat anti-human OPG $(100 \mathrm{ng} / \mathrm{ml})$, streptavidin horseradish peroxidase (R\&D systems; 1:200), and tetramethylbenzidine as substrate (R\&D systems). Assay buffer was fetal calf serum (Myoclone; Gibco, Paisley, Strathclyde, UK) and 0.1\% bovine serum albumin in PBS mixed 1:1 as recommended by the supplier. The mean recovery of two samples spiked with different concentrations of recombinant OPG was $93 \%$, range $78-101 \%$. The intra- and interassay coefficients of variation were $3.6 \%$ and $10.6 \%$ respectively. The sensitivity, defined as the mean \pm 3 s.D. of the zero standard, was calculated to be $15 \mathrm{pg} / \mathrm{ml}$. Serial dilution of two samples 1:1-1:8 gave a recovery of $126 \%$ and $127 \%$ at dilution $1: 8$.

\section{Miscellaneous}

Osteocalcin was measured by immunoradiometric assay (Incstar Corporation, Stillwater, MI, USA). The assay measures intact osteocalcin 1-49. Degradation products of the C-terminal telopeptides of Type-I collagen (CTX-I) were measured in serum with a commercial EIA (Crosslaps; Osteometer BioTech A/S, Herlev, Denmark) (17). Insulin-like growth factor-I (IGF-I; Nichols Institute Diagnostics, San Juan Capistrano, CA, USA) and cortisol (Orion Diagnostica, Epsoo Finland) were measured by radioimmunoassay. TNF $\alpha$ was quantified by EIA (detection limit $3 \mathrm{pg} / \mathrm{ml}$; BioSource Europe, Nivelles, Belgium) as described (12). $\mathrm{CD}^{+} \mathrm{T}$ cell counts in peripheral blood and HIV
RNA copies in plasma (viral load) were measured as previously described (11). The intra- and interassay coefficients of variation were $<10 \%$ for all assays.

\section{Statistical analysis}

Comparisons between variables were performed by Mann-Whitney rank sum test for unpaired data. Relationships between variables were tested using Spearman's rank correlation test and the level of significance was set at $P<0.05$. Percent differences between groups in the text are based on medians.

\section{Results}

The clinical characteristics of patients and controls are summarized in Table 1. As previously reported (18), while CS patients had increased CTX-I and decreased osteocalcin levels with no correlation between these parameters suggesting uncoupled bone remodeling, both these parameters were markedly elevated and positively correlated in acromegalic patients. In contrast, GHD patients had decreased CTX-I and osteocalcin levels that tended to correlate, indicating a coupled low turnover state. As for the 'immunologic disorders', HIV-infected patients had decreased osteocalcin and normal CTX-I levels with no correlation between these parameters, while CVI patients had increased CTX-I and no changes in osteocalcin levels with a positive correlation between these two parameters, possibly reflecting differences in bone-remodeling synchronization between these two groups of patients $(9,10)$. Finally, while CS patients had TNF $\alpha$ levels within normal limits only a modest, but significant, increase was seen in acromegalic and GHD patients, TNF $\alpha$ levels were markedly elevated in both CVI and HIV-infected patients.

\section{Serum levels of OPG in endocrine disorders}

Although there was a large variation, patients with CS had significantly increased serum levels of OPG compared with healthy controls (Fig. 1), with higher levels in women than in men (data not shown). Moreover, OPG was significantly correlated with increased cortisol levels in these patients (Fig. 2). In contrast, OPG levels in acromegalic and GHD patients were not different from healthy controls (Fig. 1). We found no correlations between OPG and TNF $\alpha$ or markers of bone metabolism in CS, GHD or acromegalic patients (Table 2).

\section{Serum levels of OPG in HIV-infected and CVI patients}

In contrast to the endocrine disorders, both immunologic disorders had raised OPG levels compared with healthy controls, with particularly high levels in HIVinfected patients $(\sim 52 \%$ increase, Fig. 1$)$. Moreover, in 


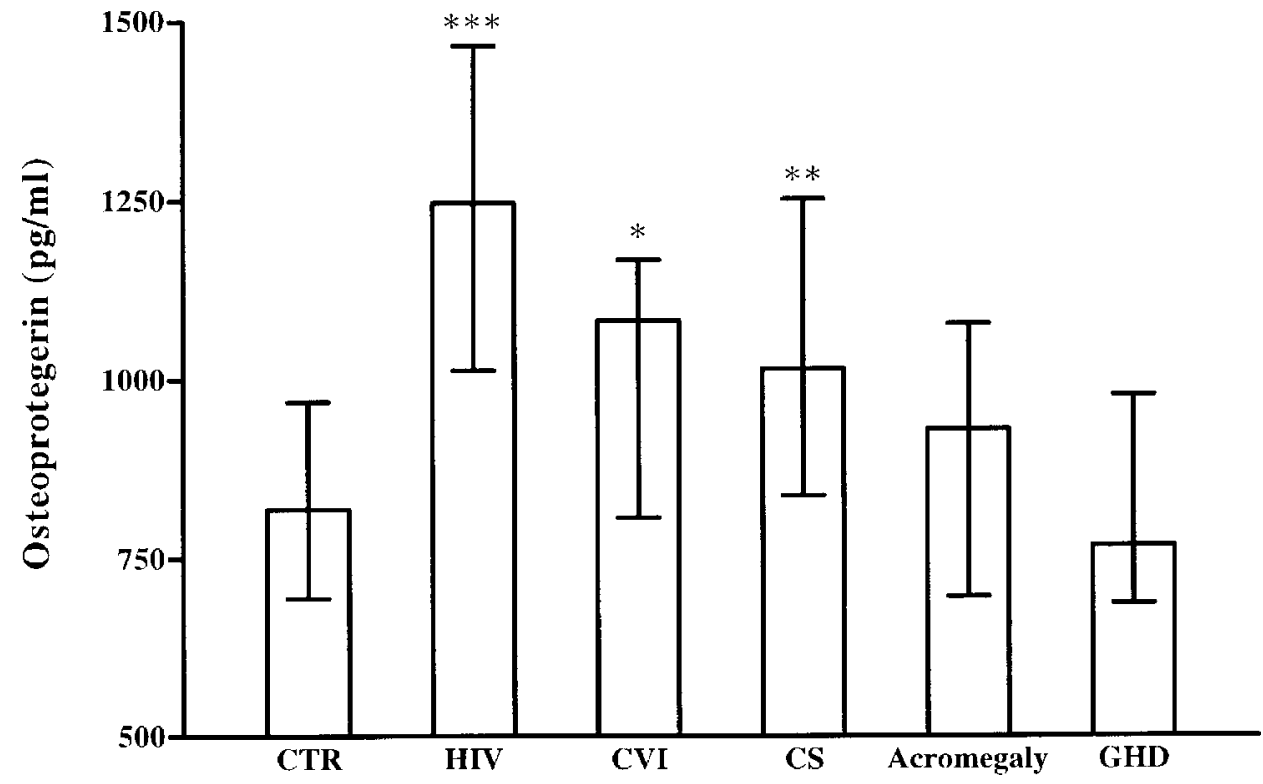

Figure 1 Serum levels of OPG in 29 HIV-infected patients, 25 patients with CVI, 34 patients with CS, 24 acromegalic patients, 16 patients with GHD and 59 healthy controls (CTR). Data are given as medians and 25th to 75th percentiles. ${ }^{*} P<0.05$, ${ }^{* \star} P<0.01$, ${ }^{\star \star \star} P<0.001$ versus controls (Mann-Whitney rank sum test).

both these groups of patients, OPG was positively correlated with TNF $\alpha$ levels, although the correlation in the CVI group did not reach statistical significance (Table 2 and Fig. 2). No relationships were found between OPG and $\mathrm{CDC}$ classification, $\mathrm{CD}^{+} \mathrm{T}$ cell counts, viral load (HIV-infected patients) or the $\mathrm{CVI}_{\text {Hyper }}$ group (CVI patients) (data not shown). However, while there was no correlation between OPG and TNF $\alpha$ in CDC group A $(r=0.09)$ and $\mathrm{B}(r=$ $0.27)$, this correlation was highly significant in the AIDS group (CDC group $\mathrm{C}, r=0.67, P=0.007)$. Similarly, while OPG and TNF $\alpha$ were uncorrelated in the $\mathrm{CVI}_{\text {Norm }}$ group $(r=-0.17)$, this correlation was highly significant in the $\mathrm{CVI}_{\text {Hyper }}$ subgroup $(r=0.73$, $P=0.005$ ). Except for a weak correlation between OPG and CTX-I in HIV-infected patients, no correlations were

Table 2 Correlations between serum levels of OPG, TNF $\alpha$ and biochemical markers of bone metabolism in 34 patients with CS, 16 patients with GHD, 24 acromegalic patients, 25 patients with CVI, 29 HIV-infected patients and 59 healthy controls.

\begin{tabular}{lccr}
\hline & \multicolumn{3}{c}{ Serum OPG correlations with: } \\
\cline { 2 - 4 } & TNF $\alpha$ & Osteocalcin & CTX-I \\
\hline CS & -0.19 & -0.19 & 0.11 \\
GHD & -0.21 & 0.31 & -0.23 \\
Acromegaly & 0.16 & 0.23 & -0.07 \\
CVI & 0.37 & -0.07 & -0.20 \\
HIV & $0.47^{\mathrm{a}}$ & -0.12 & 0.34 \\
Controls & 0.28 & $-0.35^{\mathrm{a}}$ & -0.04 \\
\hline
\end{tabular}

${ }^{\mathrm{a}} P<0.05$. found between OPG and serum markers of bone turnover in either HIV-infected or CVI patients.

No correlations were found between OPG and age in either controls or any of the patient populations as a whole, also when assessed in men and women separately.

\section{Discussion}

To investigate the possible role of circulating OPG in bone metabolism, in the present study we have measured serum OPG levels in patients with different disturbances in their bone homeostasis. The patient populations were chosen on the basis of the distinct groups they represent regarding osteoclastic-osteoblastic interaction (coupling), bone turnover, and the systemic agents mediating the abnormal effects on their skeletal metabolism.

A major finding in the present study was the elevated OPG levels in both CVI and HIV-infected patients with especially high levels in the latter group. Moreover, in these patients, high OPG levels were significantly correlated with high TNF $\alpha$ levels, with a particularly strong correlation in those with advanced disease (AIDS patients) and those with the most pronounced immune activation in vivo $\left(\mathrm{CVI}_{\mathrm{Hyper}}\right)$. Interestingly, recent in vitro studies have shown that $\mathrm{TNF} \alpha$ is a potent stimulator of OPG mRNA and protein levels in human osteoblastic cells $(19,20)$. Moreover, CD40L, another member of the TNF family with enhanced activation during HIV infection (21), may also enhance OPG levels (22). Thus, it is possible that the raised OPG

www.eje.org 


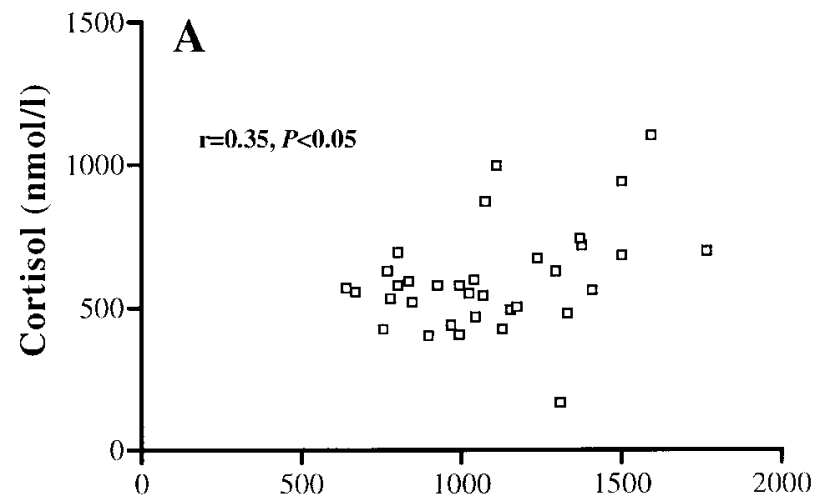

Osteoprotegerin $(\mathrm{pg} / \mathrm{ml})$

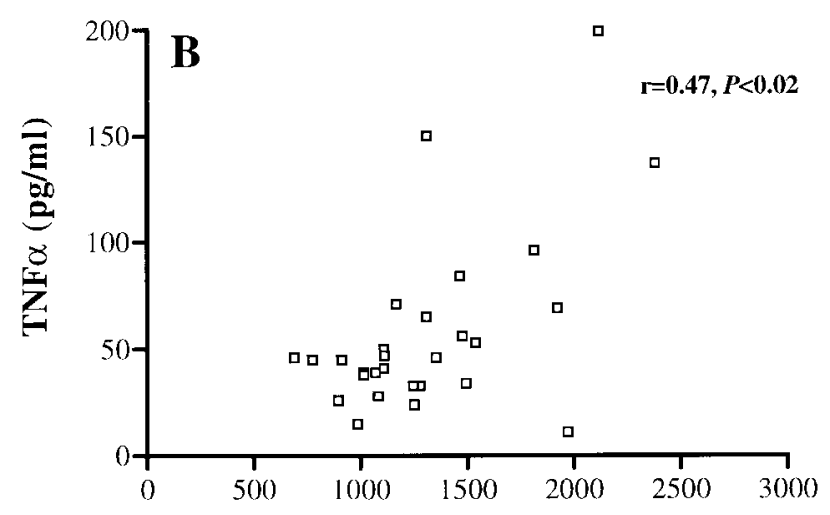

Osteoprotegerin (pg/ml)

Figure 2 Correlation (Spearman's $r$ ) between serum levels of OPG and (A) cortisol in 34 patients with CS and (B) TNF $\alpha$ in 29 HIV-infected patients.

levels in CVI and HIV-infected patients may reflect enhanced immune activation in these patients, particularly in the TNF system.

In addition to HIV-infected and CVI patients, CS patients also had raised OPG levels compared with healthy controls. However, in contrast to patients with immunologic disorders, CS patients had TNF $\alpha$ levels within normal limits and with no correlation between OPG and TNF $\alpha$. Moreover, although recent experiments have shown that glucocorticoids decrease OPG and increase RANKL production in human osteoblastic cell lines in vitro $(23,24)$, and decrease circulating $\mathrm{OPG}$ in humans during short-term treatment (25), we found a positive correlation between cortisol and OPG in CS patients. However, the outcome of short-time in vivo gluocorticoid administration may not necessarily reflect the situation in CS patients with persistently elevated cortisol levels over several months or years. Nonetheless, one possibility is that the increased serum OPG levels found in CS may reflect a compensatory response to increased bone resorption in these patients, as has been suggested in postmenopausal osteoporosis (26). In fact, it is possible that enhanced OPG levels may represent a negative feedback mechanism in disorders with enhanced osteoclastic activity.

However, acromegalic patients with markedly elevated CTX-I concentrations had normal OPG levels, indicating that enhanced OPG levels do not seem to be a uniform response to enhanced osteoclastic activity. Although, in contrast to CS, acromegalic patients, at least in cortical bone, have a positive remodeling balance $(27,28)$ and if raised OPG levels reflect a compensatory response to a negative remodeling balance, such a stimuli may be lacking in these patients. Also in GHD with a state of low bone turnover, OPG levels were within normal limits, suggesting that enhanced OPG activity may not play a pathogenic role in the inhibition of osteoclast activity in these patients. Thus, both patients with high (acromegalic) and low (GHD) GH/IGF-I levels had normal OPG levels, supporting a recent in vitro study suggesting no effect of IGF-I on OPG production in osteoblasts (29).

While enhanced OPG levels may reflect a compensatory response to enhanced osteoclast activity in some groups of patients, other explanations may also exist. When evaluating the TNF system in serum, enhanced levels of soluble TNF receptors seems to better reflect enhanced TNF activity than measurements of TNF $\alpha$ itself (11). TNF $\alpha$ may enhance the production of both OPG and RANKL $(19,20,30)$ and it is possible that, rather than reflecting enhanced inhibition of RANKL, the enhanced OPG levels may be a parameter of enhanced activity and turnover in the OPG system. In fact, to fully evaluate the OPG system in humans, RANKL levels and the expression of RANK will also have to be determined. Furthermore, both the source and significance of circulating OPGs are largely unknown and serum levels may not necessarily reflect the cytokine levels in the bone microenvironment. Nonetheless, Bekker et al. (31) recently showed that a single dose of OPG given to postmenopausal women profoundly reduced bone turnover for a sustained period, suggesting some biological effects on bone metabolism of circulating OPG.

It should be mentioned that while most studies have found an age-dependent increase of OPG, possibly representing a compensatory mechanism against agedependent bone loss, this was not found in the present study. In the study by Yano et al. (26), the largest agerelated increment was found in patients $>60$ years, while only a minor increase was observed for the younger age groups. Since the range of our control group was 23-66 years this could explain why the present study failed to discern such a relationship.

While enhanced OPG levels may be a compensatory response to enhanced osteoclast activity or negative bone remodeling balance, raised OPG levels may also be 
a parameter of enhanced activity in the OPG system, possibly correlated to enhanced activity of other members of the TNF family. Further studies are needed to clarify the role and regulation of OPG in human disease and such studies should also include other members of the OPG system.

\section{References}

1 Martin TJ, Romas E \& Gillespie MT. Interleukins in the control of osteoclast differentiation. Critical Reviews in Eukaryotic Gene Expression $1998 \mathbf{8}$ 107-123.

2 Reddy SV \& Roodman GD. Control of osteoclast differentiation. Critical Reviews in Eukaryotic Gene Expression 19988 1-17.

3 Martin TJ \& Ng KW. Mechanisms by which cells of the osteoblast lineage control osteoclast formation and activity. Journal of Cellular Biochemistry 199456 357-366.

4 Hofbauer LC, Khosla S, Dunstan CR, Lacey DL, Boyle WJ \& Riggs BL. The roles of osteoprotegerin and osteoprotegerin ligand in the paracrine regulation of bone resorption. Journal of Bone and Mineral Research 200015 2-12.

5 Simonet WS, Lacey DL, Dunstan CR, Kelley M, Chang M-S, Luthy R et al. Osteoprotegerin: a novel secreted protein involved in the regulation of bone density. Cell 199789 309-319.

6 Yasuda H, Shima N, Nakagawa N, Mochizuki S, Yano K, Fujise N et al. Identity of osteoclastogenesis inhibitory factor (OCIF) and osteoprotegerin (OPG): a mechanism by which OPG/OCIF inhibits osteoclastogenesis in vitro. Endocrinology 1998139 1329-1337.

7 Bucay N, Sarosi I, Dunstan CR, Morony S, Tarpley J, Capparelli C et al. Osteoprotegerin-deficient mice develop early onset osteoporosis and arterial calcification. Genes and Development 199812 $1260-1268$.

8 Mizuno A, Amizuka N, Irie K, Murakami A, Fujise N, Kanno T et al. Severe osteoporosis in mice lacking osteoclastogenesis inhibitory factor/osteoprotegerin. Biochemical and Biophysical Research Communications 1998247 610-615.

9 Aukrust P, Haug CJ, Ueland T, Lien E, Muller F, Espevik T et al. Decreased bone formative and enhanced resorptive markers in human immunodeficiency virus infection: indication of normalization of the bone-remodeling process during highly active antiretroviral therapy. Journal of Clinical Endocrinology and Metabolism 199984 145-150.

10 Ueland T, Froland SS, Bollerslev J \& Aukrust P. Increased levels of biochemical markers of bone turnover in relation to persistent immune activation in common variable immunodeficiency. European Journal of Clinical Investigation 200131 72-78.

11 Aukrust P, Liabakk NB, Muller F, Lien E, Espevik T \& Froland SS. Serum levels of tumor necrosis factor-alpha (TNF alpha) and soluble TNF receptors in human immunodeficiency virus type 1 infection - correlations to clinical, immunologic, and virologic parameters. Journal of Infectious Diseases 1994169 420-424.

12 Aukrust P, Lien E, Kristoffersen AK, Muller F, Haug CJ, Espevik T et al. Persistent activation of the tumor necrosis factor system in a subgroup of patients with common variable immunodeficiency - possible immunologic and clinical consequences. Blood 1996 87 674-681.

13 Centers for Disease Control and Prevention. Revised classification system for HIV infection and expanded surveillance case definition for AIDS among adolescents and adults. Morbidity and Mortality Weekly Report 200041 1-19.

14 WHO Scientific Group Report. Primary immunodeficiency diseases. Clinical and Experimental Immunology 99 (Suppl 1) $19951-24$.

15 Spickett GP, Webster AD \& Farrant J. Cellular abnormalities in common variable immunodeficiency. Immunodeficiency Reviews 19902 199-219.

16 Aukrust P, Muller F \& Froland SS. Elevated serum levels of interleukin-4 and interleukin- 6 in patients with common variable immunodeficiency (CVI) are associated with chronic immune activation and low numbers of $\mathrm{CD} 4+$ lymphocytes. Clinical Immunology and Immunopathology 199470 217-224.

17 Bonde M, Garnero P, Fledelius C, Qvist P, Delmas PD \& Christiansen C. Measurement of bone degradation products in serum using antibodies reactive with an isomerized form of an 8 amino acid sequence of the C-telopeptide of type I collagen. Journal of Bone and Mineral Research 199712 1028-1034.

18 Godang K, Ueland T \& Bollerslev J. Decreased bone area, bone mineral content, formative markers, and increased bone resorptive markers in endogenous Cushing's syndrome. European Journal of Endocrinology 1999141 126-131.

19 Hofbauer LC, Dunstan CR, Spelsberg TC, Riggs BL \& Khosla S. Osteoprotegerin production by human osteoblast lineage cells is stimulated by vitamin D, bone morphogenetic protein-2, and cytokines. Biochemical and Biophysical Research Communications $1998250776-781$.

20 Brandstrom H, Jonsson KB, Vidal O, Ljunghall S, Ohlsson C \& Ljunggren $\mathrm{O}$. Tumor necrosis factor-alpha and -beta upregulate the levels of osteoprotegerin mRNA in human osteosarcoma MG63 cells. Biochemical and Biophysical Research Communications $1998248454-457$.

21 Muller F, Aukrust P, Nordoy I \& Froland SS. Possible role of interleukin-10 (IL-10) and CD40 ligand expression in the pathogenesis of hypergammaglobulinemia in human immunodeficiency virus infection: modulation of IL-10 and Ig production after intravenous Ig infusion. Blood 199892 3721-3729.

22 Yun TJ, Chaudhary PM, Shu GL, Frazer JK, Ewings MK, Schwartz SM et al. OPG/FDCR-1, a TNF receptor family member, is expressed in lymphoid cells and is up-regulated by ligating CD40. Journal of Immunology $1998 \mathbf{1 6 1}$ 6113-6121.

23 Hofbauer LC, Gori F, Riggs BL, Lacey DL, Dunstan CR, Spelsberg TC et al. Stimulation of osteoprotegerin ligand and inhibition of osteoprotegerin production by glucocorticoids in human osteoblastic lineage cells: potential paracrine mechanisms of glucocorticoid-induced osteoporosis. Endocrinology 1999 $1404382-4389$.

24 Vidal NO, Brandstrom H, Jonsson KB \& Ohlsson C. Osteoprotegerin mRNA is expressed in primary human osteoblast-like cells: down-regulation by glucocorticoids. Journal of Endocrinology 1998159 191-195.

25 Sasaki N, Kusano E, Ando Y, Yano K, Tsuda E \& Asano Y. Glucocorticoid decreases circulating osteoprotegerin (OPG): possible mechanism for glucocorticoid induced osteoporosis. Nephrology, Dialysis, Transplantation 200116 479-482.

26 Yano K, Tsuda E, Washida N, Kobayashi F, Goto M, Harada A et al. Immunological characterization of circulating osteoprotegerin/osteoclastogenesis inhibitory factor: increased serum concentrations in postmenopausal women with osteoporosis. Journal of Bone and Mineral Research 199914 518-527.

27 Halse J, Melsen F \& Mosekilde L. Iliac crest bone mass and remodelling in acromegaly. Acta Endocrinologica 198197 18-22.

28 Kotzmann H, Bernecker P, Hubsch P, Pietschmann P, Woloszczuk W, Svoboda T et al. Bone mineral density and parameters of bone metabolism in patients with acromegaly. Journal of Bone and Mineral Research 19938 459-465.

29 Hofbauer LC. Osteoprotegerin ligand and osteoprotegerin: novel implications for osteoclast biology and bone metabolism. European Journal of Endocrinology 1999141 195-210.

30 Hofbauer LC, Lacey DL, Dunstan CR, Spelsberg TC, Riggs BL \& Khosla S. Interleukin-1beta and tumor necrosis factor-alpha, but not interleukin-6, stimulate osteoprotegerin ligand gene expression in human osteoblastic cells. Bone 199925 255-259.

31 Bekker PJ, Holloway D, Nakanishi A, Arrighi M, Leese PT \& Dunstan CR. The effect of a single dose of osteoprotegerin in postmenopausal women. Journal of Bone and Mineral Research $200116348-360$.

Received 19 January 2001

Accepted 11 July 2001 